\title{
Association of fibroblast growth factor 23 and a-klotho in hemodialysis patients during administration of ferric citrate hydrate: post hoc analysis of ASTRIO study
}

\author{
Kyoko Ito ${ }^{1}$, Keitaro Yokoyama², Masaaki Nakayama ${ }^{3}$, Masafumi Fukagawa ${ }^{4}$ and Hideki Hirakata ${ }^{5}$
}

\begin{abstract}
Background: Fibroblast growth factor-23 (FGF23) and a-klotho are associated with anemia in patients with chronic kidney disease. In this post hoc analysis of the ASTRIO study (UMIN000019176), we investigated the relationship between FGF23 and a-klotho during treatment with an iron-based phosphate binder, ferric citrate hydrate (FC), compared with non-iron-based phosphate binders in hemodialysis (HD) patients. We examined the effect of iron absorption by FC on the relationship between FGF23 and a-klotho. There have been few clinical studies evaluating these biomarkers simultaneously in HD patients.
\end{abstract}

Methods: The ASTRIO study was a 24-week, randomized, open-label, multicenter trial. HD patients taking non-ironbased phosphate binder(s) were randomized at a 1:1 ratio to continue other binder(s) (control group) or switch to FC (FC group). Serum phosphate (P) and hemoglobin ( $\mathrm{Hb}$ ) were maintained within 3.5-6.0 mg/dL and 10-12 g/dL, respectively. Plasma levels of intact FGF23 (i-FGF23), C-terminal FGF23 (c-FGF23), and a-klotho were measured, as were iron-related parameters. Association analyses of FGF23 and a-klotho were conducted.

Results: Patients were randomized to FC $(n=48)$ and control $(n=45)$ groups. Serum ferritin significantly increased from baseline to end-of-treatment (EOT) in the FC group, compared with the control group (adjusted mean difference [95\% confidence interval]: $79.5[44.7,114.4] \mathrm{ng} / \mathrm{mL} ; p<0.001)$. The mean change from baseline to EOT in c-FGF23 was significantly different between the FC and control groups (mean \pm standard deviation (SD): $-0.2 \pm 0.8 \mathrm{log}$ e $\mathrm{pg} / \mathrm{mL}$ vs. $0.2 \pm 0.8 \log _{\mathrm{e}} \mathrm{pg} / \mathrm{mL}$, respectively; $p=0.04$ ). The mean change from baseline to EOT in i-FGF23 and a-klotho were not significantly different between the FC and control groups (mean $\pm S D:-0.1 \pm 0.8 \log _{e} \mathrm{pg} / \mathrm{mL}$ vs. $0.1 \pm 0.9 \mathrm{log}_{\mathrm{e}} \mathrm{pg} / \mathrm{mL}$; $p=0.33$, and $2.0 \pm 91.5 \mathrm{pg} / \mathrm{mL}$ vs. $-8.9 \pm 145.3 ; p=0.58$, respectively). However, both forms of FGF23 and a-klotho were not significantly associated with each other in both groups.

Conclusions: Iron absorbed via FC administration in HD patients did not influence the correlation relationship between plasma levels of FGF23 and a-klotho under the condition of serum P and $\mathrm{Hb}$ were maintained.

Trial registration: ASTRIO study (UMIN000019176, registered at UMIN Clinical Trials Registry on October 1, 2015).

Keywords: ASTRIO study, Ferric citrate hydrate, FGF23, a-Klotho, Hemodialysis, iron-based phosphate binder

*Correspondence: keitaro@jikei.ac.jp

${ }^{2}$ Health Care Center, Harumi Toriton Clinic, The Jikei University Hospital,

1-8-8 Harumi, Chuo-ku, Tokyo 104-0053, Japan

Full list of author information is available at the end of the article

\section{Background}

In patients with chronic kidney disease (CKD), hyperphosphatemia and anemia are common complications associated with vascular calcification and elevated 
mortality rates $[1,2]$. Ferric citrate hydrate (FC, Riona ${ }^{\circledR}$, Torii Pharmaceutical Co., Ltd., Tokyo, Japan) is an ironbased phosphate binder approved to treat hyperphosphatemia in patients with non-dialysis-dependent and dialysis-dependent CKD. For patients with CKD, hyperphosphatemia is the most important risk factor for vascular calcification. In the past 10 years, fibroblast growth factor-23 (FGF23) and $\alpha$-klotho have been recognized as important contributors to phosphate homeostasis [3].

FGF23 is an endocrine hormone expressed in bone [4-6] that plays an important role in the maintenance of phosphate and calcium balance by binding to FGF receptors expressed in the kidney [7]. It also regulates the secretion of parathyroid hormone to ensure a normal level of serum calcium. In patients with CKD, plasma FGF23 levels increase in response to worsening kidney function. In patients with dialysis-dependent CKD, despite these higher levels of plasma FGF23, hyperphosphatemia and hyperparathyroidism are observed. Elevated plasma FGF23 is an independent risk factor for CKD progression, anemia, and reduced hemoglobin $(\mathrm{Hb})$; it is also associated with cardiovascular events [8, 9]. Recently, iron homeostasis, inflammation, and erythropoiesis have been associated with FGF23 regulation [6].

Alpha-klotho ( $\alpha$-klotho) is a multifunctional protein expressed in the kidney, with two forms: full-length transmembrane $\alpha$-klotho (mKL) and soluble secreted $\alpha$-klotho (sKL) [10]. mKL acts as a coreceptor for FGF23, forming an FGF receptor-klotho complex in the kidney and parathyroid gland to increase the receptor binding affinity to FGF23 [11, 12]. This complex enhances urinary phosphate excretion while regulating phosphate and calcium homeostasis. sKL is generated by alternative splicing or cleavage from the membrane form [13, 14] and is detected in both blood and cerebrospinal fluid. sKL is presumed to have cell-protective effects including the inhibition of apoptosis, oxidative stress, and senescence [15]. The kidney is a major source of sKL; notably, reduced levels of circulating $\mathrm{SKL}$ are observed in older people and patients with CKD. However, it is unknown whether reduced $\alpha$-klotho expression is directly caused by the absence of sKL and its protective effects; alternatively, this change in expression may be indirectly caused by the loss of $\mathrm{mKL}$, which leads to elevated levels of phosphate or FGF23. The potential for $\alpha$-klotho to serve as a biomarker of kidney function has been suggested in recent decades on the basis of reduced renal production of $\alpha$-klotho in patients with CKD [16-18]; moreover, reduced levels of sKL are reportedly associated with the prevalence of anemia in patients with CKD [19].

In a meta-analysis in 2018, five of seven studies involving patients with non-dialysis-dependent CKD demonstrated a negative correlation between FGF23 and $\alpha$-klotho [20]. Despite the known functional relationship between FGF23 and $\alpha$-klotho, there have been few clinical studies evaluating these biomarkers simultaneously in patients with dialysis-dependent-CKD, as well as studies concerning the effects of drugs such as iron-containing products.

Previously, the effect of FC on renal anemia was investigated by comparing administration of $\mathrm{FC}$ with that of non-iron-based phosphate binders in the randomized, prospective, multicenter ASTRIO study that involved patients with CKD and hyperphosphatemia who were undergoing hemodialysis (HD) and erythropoiesisstimulating agent (ESA) therapy [21]. In that study, the enhancement of serum ferritin from baseline to the end of treatment (EOT), reductions in ESA dose per week from baseline to EOT, and changes in plasma levels of C-terminal FGF23 (c-FGF23) from baseline to EOT were greater in the FC group than in the control group. Levels of $\mathrm{Hb}$ and serum phosphate $(\mathrm{P})$ were maintained at $10-12 \mathrm{~g} / \mathrm{dL}$ and $3.5-6.0 \mathrm{mg} / \mathrm{dL}$, respectively, in both groups during that study. The results suggested that iron from FC was partially absorbed and contributed to the reduced dose of ESA, while improving c-FGF23 levels.

In the current study, we investigated whether iron absorbed via FC administration could influence the relationship between FGF23 and $\alpha$-klotho by using data obtained from the ASTRIO study [21].

\section{Methods \\ Study design}

The ASTRIO study was a randomized, open-label, active-controlled, multicenter, parallel-arm, 24-week trial conducted at 17 medical institutions in Japan from November 2015 to January 2017 (UMIN000019176, registered at UMIN Clinical Trials Registry on October $1,2015)$. Detailed methods were provided in a previous report [21]. This study was conducted in accordance with the Declaration of Helsinki. The protocol was reviewed and approved by an independent ethics committee and the Institutional Review Board of The Jikei University School of Medicine (approval number: 27-087 (7972). All participants provided written informed consent before starting the study.

\section{Patients}

Participants were adult (age $\geq 20$ years) patients with CKD who were undergoing HD for at least 12 weeks before registration, receiving one or more non-ironbased phosphate binders to treat hyperphosphatemia (monotherapy or combination therapy of sevelamer hydrochloride, lanthanum carbonate hydrate, bixalomer, and/or precipitated calcium carbonate) for at least 4 weeks before registration and were receiving an ESA 


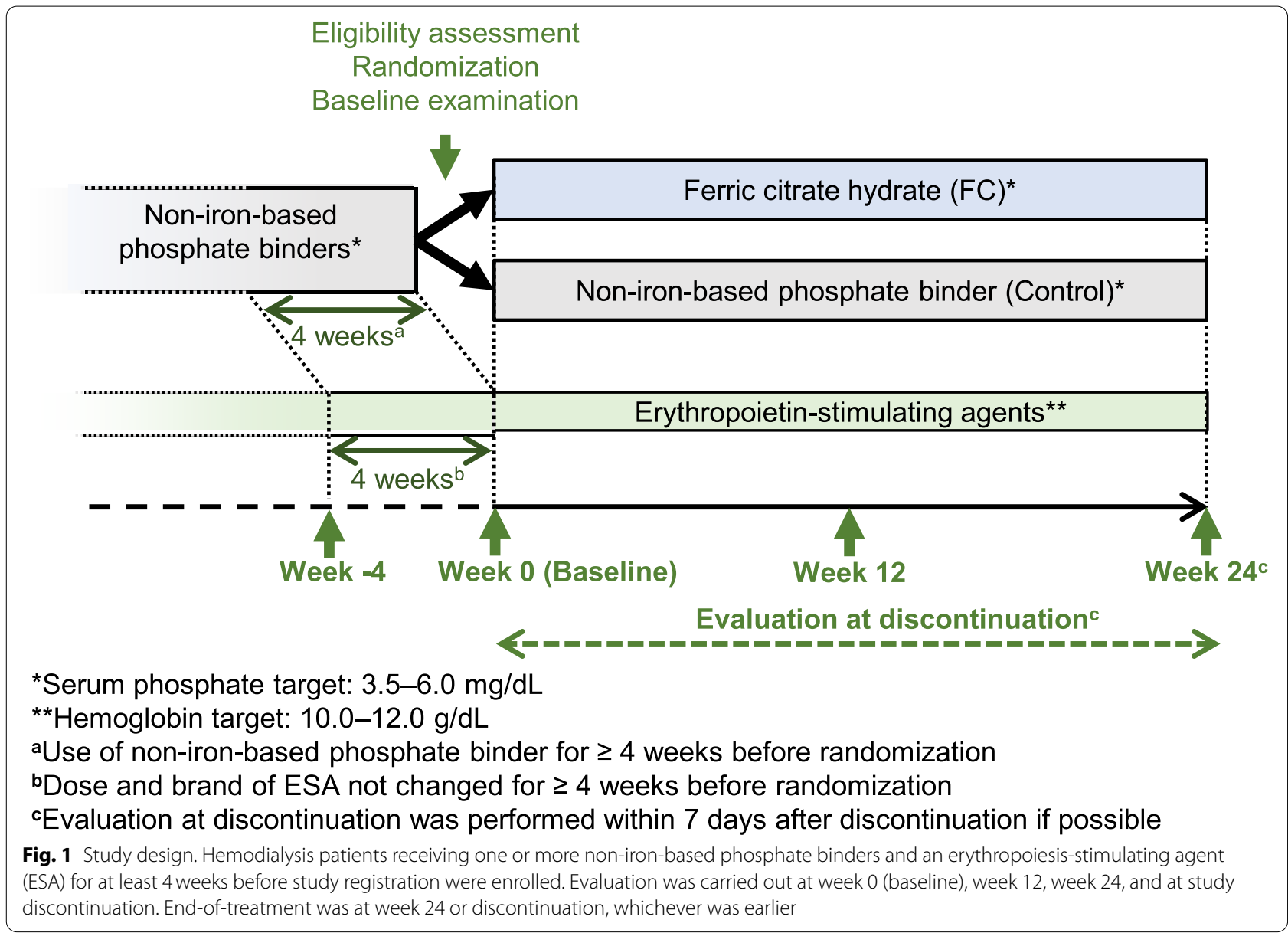

(epoetin alfa, epoetin beta, darbepoetin alfa, or epoetin beta pegol) to treat renal anemia with constant dose of a single brand for at least 4 weeks before registration.

\section{Treatment}

Eligible patients were randomly assigned to the $\mathrm{FC}$ or control groups with a 1:1 allocation ratio using a permuted block method (Fig. 1).

The starting dose of FC was $1500 \mathrm{mg} /$ day (two tablets of $250 \mathrm{mg}$ FC, three times/day after a meal; one tablet contained approximately $60 \mathrm{mg}$ ferric iron). The dose was adjusted weekly with a maximum dose of $6000 \mathrm{mg} /$ day as required to maintain target serum P levels of $3.5-6.0 \mathrm{mg} /$ $\mathrm{dL}$ in accordance with the clinical practice guidelines of the Japanese Society for Dialysis Therapy (JSDT) [22]. An ESA was administered to maintain target $\mathrm{Hb}$ levels of $10.0-12.0 \mathrm{~g} / \mathrm{dL}$ in accordance with JSDT guidelines for renal anemia in patients with CKD [23]. All oral iron preparations other than FC were prohibited; however, intravenous iron preparations were permitted if desired by the study physician, for instance, in a case of serum ferritin $<100 \mathrm{ng} / \mathrm{mL}$ and TSAT $<20 \%$.

\section{Evaluation}

In the ASTRIO study, patients were evaluated for safety and efficacy at 4-week intervals until EOT (at week 24 or the day of discontinuation; Fig. 1). The primary endpoint was the mean change in ESA dose per week from baseline to EOT. The secondary endpoints included ironrelated parameters at 4-week intervals and CKD-mineral bone disorder parameters, including plasma intact FGF23 (i-FGF23), c-FGF23, and $\alpha$-klotho measured at baseline, weeks 12 and 24, and at study discontinuation. Blood samples were collected before hemodialysis. These values were used for post hoc analysis in the current study. Detailed safety and efficacy evaluation items were described previously [21].

The plasma levels of i-FGF23, c-FGF23, and $\alpha$-klotho were determined at LSI Medience Corporation (Tokyo, Japan). Levels of i-FGF23 were measured using the FGF23 ELISA kit (Kainos, Tokyo, Japan); c-FGF23, using the FGF23 Multi-Matrix ELISA kit (Biomedica Immunoassays, Vienna, Austria); and $\alpha$-klotho, using the Human Soluble $\alpha$-Klotho Assay kit (IBL International $\mathrm{GmbH}$, Hamburg, Germany). All other biomarkers, including 
serum $\mathrm{P}$ and $\mathrm{Hb}$, were measured using a standard chemistry autoanalyzer.

\section{Statistical analyses}

The intended sample size was estimated to be 90 patients, which provided at least $80 \%$ power to detect the difference in mean changes of ESA dose per week from baseline to EOT (the primary endpoint) between two treatment groups with a type I error of 5\% according to Wilcoxon rank sum test analysis; the results of two Japanese phase III trials with FC administration for 28 and 52 weeks were used as reference data. Baseline characteristics were summarized as descriptive statistics; differences between the FC and control groups were compared using either Student's $t$-test (continuous variables) or Fisher's exact test (categorical variables). Mean differences in biomarker levels between the FC and control groups were evaluated using analysis of covariance with baseline values as a covariate. Associations of the plasma levels or degree of change from baseline to EOT of $\alpha$-klotho vs. those of i-FGF23 or c-FGF23 in each treatment group were evaluated by calculating Pearson's correlation coefficient. Statistical analyses were performed using SAS version 9.3 or 9.4 (SAS Institute Inc., Cary, NC, USA).

\section{Results}

\section{Baseline characteristics and patient flow}

The recruitment period was from November 2015 to March 2016. After eligibility screening, 93 patients were enrolled and randomized (FC group, $n=48$; control group, $n=45$ ). Two patients in the $\mathrm{FC}$ group did not receive study treatment and 75/93 (FC group, $n=34 / 48$; control group, $n=41 / 45$ ) patients completed the 24-week study; however, one patient in each group was excluded from the analyses because of missing data. For the EOT evaluation, data from $82 / 93$ patients were available (FC group, $n=40 / 48$; control group, $n=42 / 45$ ). The patient flow is summarized in Fig. 2.

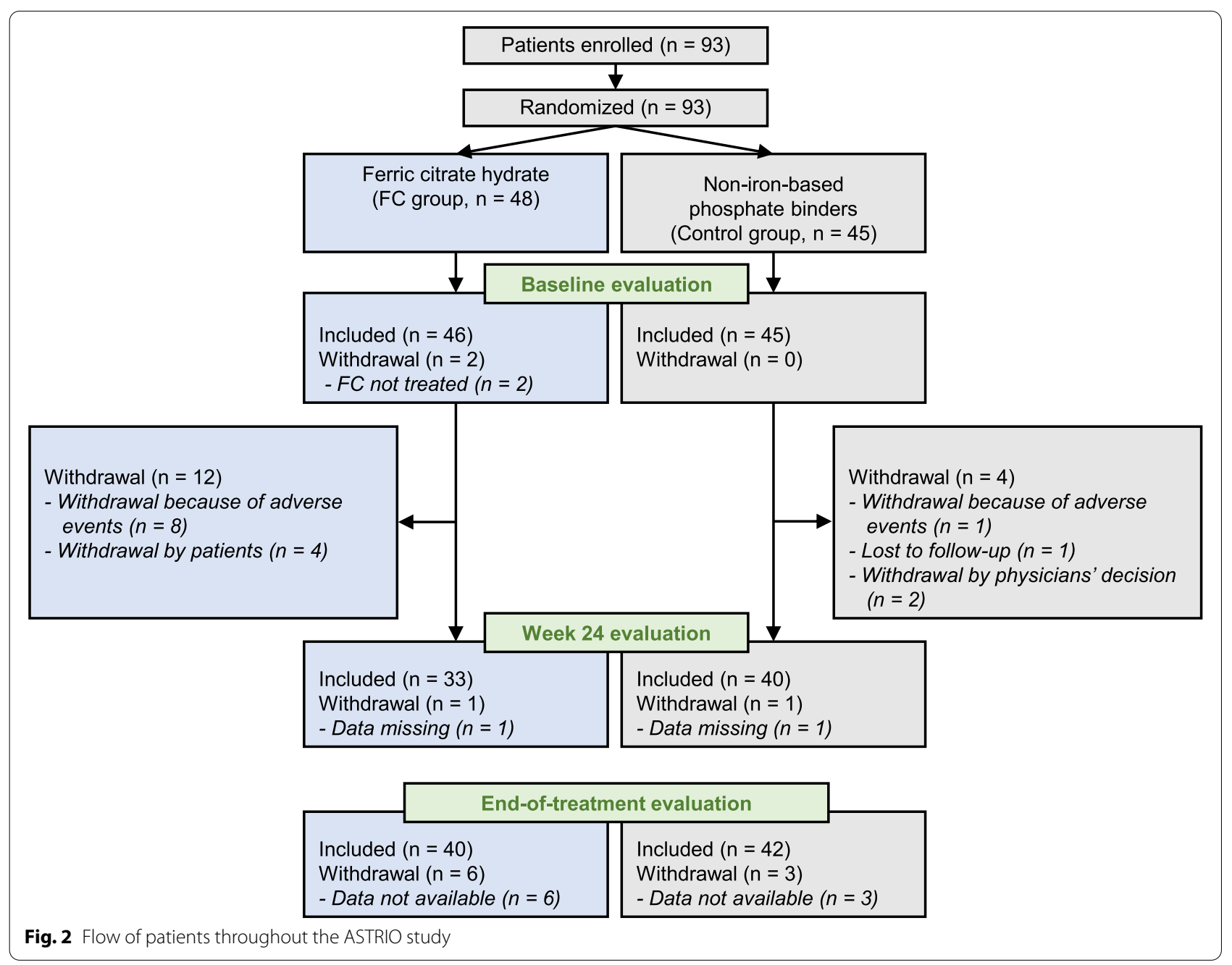


The main baseline characteristics are summarized in Table 1 . There were no significant differences in patient characteristics between the groups.

\section{Changes in biomarkers}

The changes in biomarkers from baseline to EOT are summarized in Table 2. The levels of serum $P$ and $\mathrm{Hb}$ were maintained and there were no significant differences in mean level changes from baseline to EOT between the groups. Regarding iron-related parameters, mean level changes from baseline to EOT were greater in the FC group than in the control group: adjusted mean differences were $79.5 \mathrm{ng} / \mathrm{mL}(p<0.001)$ in serum ferritin and $9.0 \%(p<0.001)$ in transferrin saturation. The levels of i-FGF23 and c-FGF23 from baseline to EOT decreased slightly in the FC group and

Table 1 Baseline characteristics of participants in the ASTRIO study (modified from Yokoyama et al., 2019 [21])

\begin{tabular}{|c|c|c|c|}
\hline Characteristic & $\begin{array}{l}\text { FC group } \\
(n=46)\end{array}$ & $\begin{array}{l}\text { Control group } \\
(n=45)\end{array}$ & $p$ value $^{*}$ \\
\hline Age [years], mean (SD) & $63.3(10.0)$ & $62.7(12.7)$ & 0.78 \\
\hline Body weight before dialysis [kg], mean (SD) & $60.02(10.67)$ & $62.91(13.61)$ & 0.26 \\
\hline Male sex, n (\%) & $30(65.2)$ & $36(80.0)$ & 0.16 \\
\hline \multicolumn{4}{|c|}{ Classification of drugs for hyperphosphatemia, n (\%) } \\
\hline Precipitated calcium carbonate & $30(65.2)$ & $28(62.2)$ & 0.83 \\
\hline Lanthanum carbonate hydrate & $21(45.7)$ & $21(46.7)$ & 1.00 \\
\hline Sevelamer hydrochloride & $6(13.0)$ & $10(22.2)$ & 0.28 \\
\hline Bixalomer & $4(8.7)$ & $5(11.1)$ & 0.74 \\
\hline Other & $0(0)$ & $0(0)$ & - \\
\hline Use of IV iron preparations, $\mathrm{n}(\%)$ & $4(8.7)$ & $6(13.3)$ & 0.52 \\
\hline Serum $P[\mathrm{mg} / \mathrm{dL}]$, mean (SD) & $5.36(1.15)$ & $5.15(1.25)$ & $0.42^{* *}$ \\
\hline $\mathrm{Hb}[\mathrm{g} / \mathrm{dL}]$, mean (SD) & $10.52(0.70)$ & $10.47(0.94)$ & $0.78^{* *}$ \\
\hline TSAT [\%], mean (SD) & $23.0(9.8)$ & $21.2(9.3)$ & $0.36^{* *}$ \\
\hline Serum ferritin $[\mathrm{ng} / \mathrm{mL}]$, mean (SD) & $105.7(85.5)$ & $85.6(85.8)$ & $0.27^{* *}$ \\
\hline ESA dose $[$ [U/week], mean (SD) & $5735.4(4933.3)$ & $5848.1(4082.8)$ & $0.91^{* *}$ \\
\hline i-FGF23 [pg/mL], mean (SD) & $11,774.5(14,561.0)$ & $7883.1(10,243.8)$ & $0.14^{* *}$ \\
\hline c-FGF23 [pg/mL], mean (SD) & $1610.6(2370.9)$ & $1185.8(1608.6)$ & $0.32^{* *}$ \\
\hline a-Klotho $[\mathrm{pg} / \mathrm{mL}]$, mean (SD) & $400.2(107.1)$ & $442.8(239.1)$ & $0.27^{* *}$ \\
\hline
\end{tabular}

* Fisher's exact test; ${ }^{* *}$ Student's $t$-test; ${ }^{\circ}$ Epoetin $200 \mathrm{IU}$, darbepoetin $1 \mu \mathrm{g}$, and epoetin beta pegol $1 \mu \mathrm{g}$ are equivalent

Abbreviations: c-FGF23 C-terminal FGF23; ESA erythropoiesis-stimulating agent; FC ferric citrate hydrate; $H b$ hemoglobin; $i$-FGF23 intact fibroblast growth factor-23; $I V$ intravenous; $P$ phosphate; $S D$ standard deviation; TSAT transferrin saturation

Table 2 Changes in biomarker levels in the ASTRIO study (modified from Yokoyama et al., 2019 [21])

\begin{tabular}{|c|c|c|c|c|c|c|c|c|c|}
\hline \multirow[t]{2}{*}{ Variable } & \multicolumn{3}{|c|}{ FC group $(n=40)$} & \multicolumn{3}{|c|}{ Control group $(n=42)$} & \multirow[t]{2}{*}{ AMD } & \multirow[t]{2}{*}{$95 \% \mathrm{Cl}$} & \multirow[t]{2}{*}{$p$ value $^{*}$} \\
\hline & Baseline & EOT & Change & Baseline & EOT & Change & & & \\
\hline Serum P [mg/dL] & $5.36(1.15)$ & $5.65(1.39)$ & $0.24(1.59)$ & $5.15(1.25)$ & $5.04(1.32)$ & $-0.17(1.53)$ & 0.55 & $-0.03,1.13$ & 0.06 \\
\hline $\mathrm{Hb}[\mathrm{g} / \mathrm{dL}]$ & $10.52(0.70)$ & $10.90(1.23)$ & $0.45(1.33)$ & $10.47(0.94)$ & $10.74(1.14)$ & $0.34(1.73)$ & 0.17 & $-0.34,0.69$ & 0.51 \\
\hline TSAT [\%] & $23.0(9.8)$ & $31.8(13.6)$ & $8.6(12.1)$ & $21.2(9.3)$ & $21.8(10.8)$ & $0.5(11.8)$ & 9.0 & $4.0,13.9$ & $<0.001$ \\
\hline Serum ferritin $[\mathrm{ng} / \mathrm{mL}]$ & $105.7(85.5)$ & $181.2(108.2)$ & $79.0(81.5)$ & $85.6(85.8)$ & $89.0(97.4)$ & $2.9(79.3)$ & 79.5 & $44.7,114.4$ & $<0.001$ \\
\hline $\begin{array}{l}\text { i-FGF23 } \\
{\left[\log _{e} p g / m L\right]^{* *}}\end{array}$ & $8.5(1.5)$ & $8.4(1.5)$ & $-0.1(0.8)$ & $8.1(1.5)$ & $8.3(1.5)$ & $0.1(0.9)$ & $0.8^{* * *}$ & $0.6,1.2$ & 0.33 \\
\hline $\begin{array}{l}c-F G F 23 \\
{\left[\log _{e} p g / m L\right]^{* *}}\end{array}$ & $6.6(1.3)$ & $6.3(1.5)$ & $-0.2(0.8)$ & $6.3(1.3)$ & $6.5(1.3)$ & $0.2(0.8)$ & $0.7^{* * *}$ & $0.5,1.0$ & 0.04 \\
\hline a-Klotho [pg/mL] & $400.2(107.1)$ & $399.7(129.3)$ & $2.0(91.5)$ & $442.8(239.1)$ & $440.3(153.5)$ & $-8.9(145.3)$ & -11.1 & $-51.2,29.0$ & 0.58 \\
\hline
\end{tabular}

All data are shown as mean (standard deviation)

${ }^{*}$ Analysis of covariance (covariate: baseline); ${ }^{* *}$ Logarithmic transformation; ${ }^{* * *}$ Exponential form of logarithmic adjusted mean difference

Abbreviations: AMD adjusted mean difference (FC - Control); Hb hemoglobin; C-FGF23 C-terminal FGF23; Cl confidence interval; EOT end-of-treatment (day of observation at week 24 or discontinuation); FC ferric citrate hydrate; $i$-FGF23 intact fibroblast growth factor-23; $P$ phosphate; TSAT transferrin saturation 
increased in the control group. The exponential form of the logarithmic adjusted mean difference in i-FGF23 was not significantly different between the groups $(0.8$; $p=0.33$ ). Conversely, the exponential form of the logarithmic adjusted mean difference in c-FGF23 between the groups was statistically significant $(0.7 ; p=0.04)$.

\section{Time-course changes in FGF23 and a-klotho}

There were no significant time-course changes in the levels of i-FGF23, c-FGF23, or $\alpha$-klotho (Fig. 3). Figure 4 shows time-course changes in the difference from baseline to EOT in i-FGF23, c-FGF23, and $\alpha$-klotho. The levels of i-FGF23 and c-FGF23 in the FC group tended to decrease from baseline, while those in the control group remained stable during the treatment period (Fig. 4a). The changes in c-FGF23 from baseline to EOT were significantly different between the FC and control groups (mean: -0.2 [95\% confidence interval: $-0.5,0.0] \log _{\mathrm{e}} \mathrm{pg} / \mathrm{mL}$ vs. mean: 0.2 [95\% confidence interval: $-0.1,0.4] \log _{\mathrm{e}} \mathrm{pg} / \mathrm{mL}$, respectively; $p=0.04$ ) (Fig. 4b). There were no changes in $\alpha$-klotho from baseline to EOT in either group (Fig. 4c).

\section{Correlation analysis}

The values of $\alpha$-klotho, i-FGF23, and c-FGF23 were scatter plotted to analyze associations between $\alpha$-klotho and i-FGF23 or c-FGF23 in terms of baseline levels (Fig. 5) and changes from baseline to EOT (Fig. 6). At baseline, there were no significant associations: $\alpha$-klotho vs. $\mathrm{i}-\mathrm{FGF} 23$ in the FC group $(\mathrm{r}=0.11$, $p=0.47$; Fig. 5a); $\alpha$-klotho vs. i-FGF23 in the control group ( $\mathrm{r}=0.03, p=0.82$; Fig. $5 \mathrm{~b}) ; \alpha$-klotho vs. c-FGF23 in the FC group ( $\mathrm{r}=0.12, p=0.44$; Fig. $5 \mathrm{c})$; and $\alpha$-klotho vs. c-FGF23 in the control group $(\mathrm{r}=0.02$, $p=0.91$; Fig. 5d). Similarly, there were no significant associations in the degree of changes from baseline to EOT in any of the comparisons analyzed: $\alpha$-klotho vs. i-FGF23 in the FC group ( $r=0.16, p=0.33$; Fig. 6a); $\alpha$-klotho vs. i-FGF23 in the control group $(r=0.03$, $p=0.84$; Fig. $6 \mathrm{~b}$ ); $\alpha$-klotho vs. c-FGF23 in the FC group $(\mathrm{r}=0.14, p=0.38$; Fig. $6 \mathrm{c})$; and $\alpha$-klotho vs. c-FGF23 in the control group $(\mathrm{r}=-0.13, p=0.43$; Fig. $6 \mathrm{~d})$.

\section{Safety}

The frequency of adverse events was similar in both groups and no serious treatment-related adverse events were observed. However, the discontinue rate due to $\mathrm{AE}$ were higher in the $\mathrm{FC}$ group $(n=8)$ than in the control group $(n=1)$ (Fig. 2).

\section{Discussion}

FGF23 has been inversely correlated with sKL in healthy human participants [24] and patients with non-dialysisdependent CKD [20, 25]. In addition, both FGF23 and $\alpha$-klotho are reportedly associated with renal anemia [6, 19]. To the best of our knowledge, there have been few clinical studies evaluating these biomarkers simultaneously in patients with dialysis-dependent CKD. Here, we used data obtained from the ASTRIO study to evaluate the relationship between FGF23 and $\alpha$-klotho during treatment with an iron-based phosphate binder (FC), compared with non-iron-based phosphate binders, in patients with CKD who were undergoing HD. In the ASTRIO study, levels of serum ferritin significantly increased and c-FGF23 significantly decreased in the FC group compared with the control group, while the serum $\mathrm{P}$ and $\mathrm{Hb}$ were maintained within the respective ranges of $3.5-6.0 \mathrm{mg} / \mathrm{dL}$ and $10-12 \mathrm{~g} / \mathrm{dL}$. Notably, we did not find any correlation relationship between FGF23 and $\alpha$-klotho in either group.

The level of FGF23 reportedly increases [26], while the level of $\alpha$-klotho decreases [17], with disease progression in patients with CKD. A previous randomized trial of sevelamer carbonate measured levels of FGF23 and $\alpha$-klotho in patients with non-dialysis-dependent CKD; it did not show any treatment effects on the levels of i-FGF23, c-FGF23, or $\alpha$-klotho in patients for whom serum $P$ did not significantly change [27]. FC was reported to reduce FGF23 in patients with CKD who were non-dialysis-dependent [28] and those who were undergoing HD [29], when serum P significantly decreased. Among patients in the ASTRIO study who exhibited stable serum $\mathrm{P}$ and $\mathrm{Hb}$, only c-FGF23 was significantly decreased in the FC group, compared with the control group. Taken together, these findings imply that iron absorbed by FC treatment led to reduced FGF23 production and subsequent cleavage, because c-FGF23 is reported to be increased by stimulating an FGF23 production and cleavage under the iron deficiency condition $[6,21]$.

The failure of FC to increase the level of sKL among patients in the ASTRIO study may be attributed to the elevated baseline levels of FGF23 in the study population. In patients undergoing HD, FGF23 levels are high [26]. In addition, initiation of HD reduced FGF23 levels but did not influence sKL levels [30], which suggests that it may be difficult to alter sKL levels in patients undergoing HD. The $\alpha$-klotho protein enhances FGF23 signaling in the kidney by increasing receptor affinity [12] and regulates FGF23 synthesis in bone [31]. Therefore, klotho might be suppressed by a negative feedback mechanism induced by the high level of FGF23 in these patients. The reduction of c-FGF23 by FC in the 24-week ASTRIO study was 
a

Time-course change

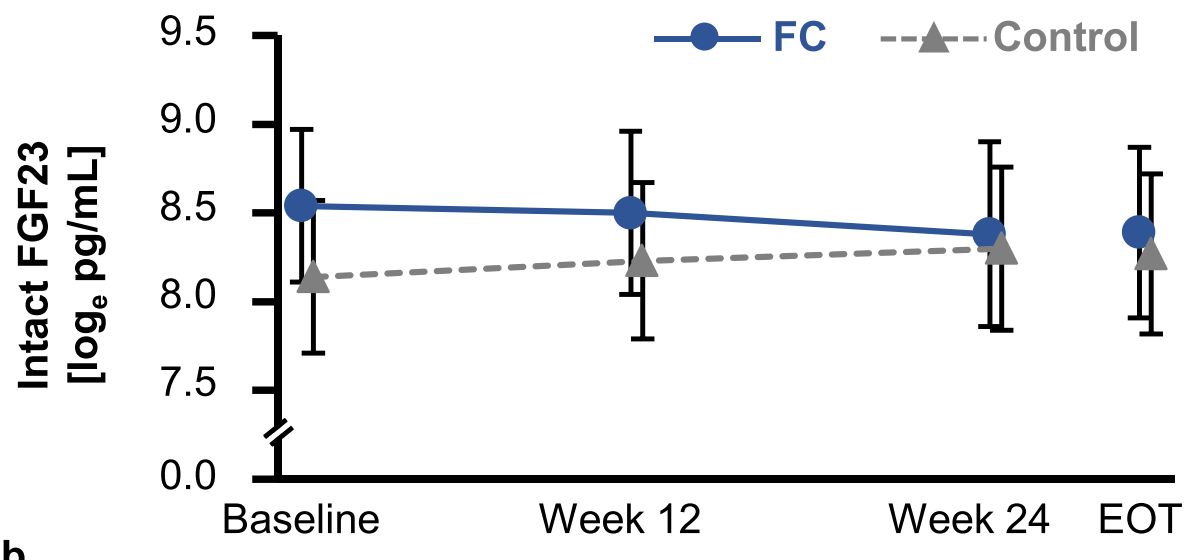

b

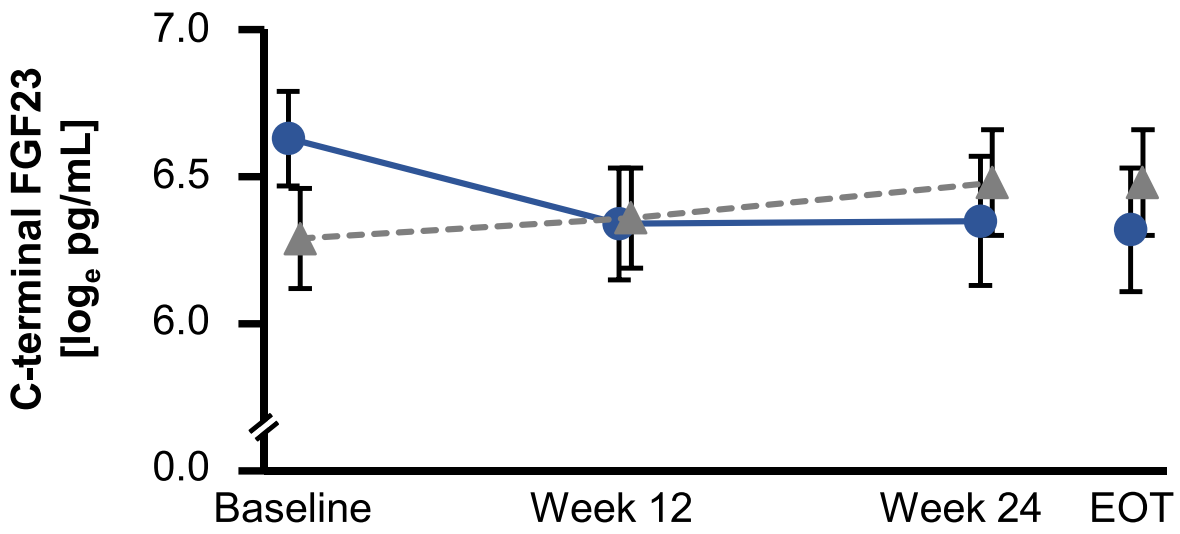

C

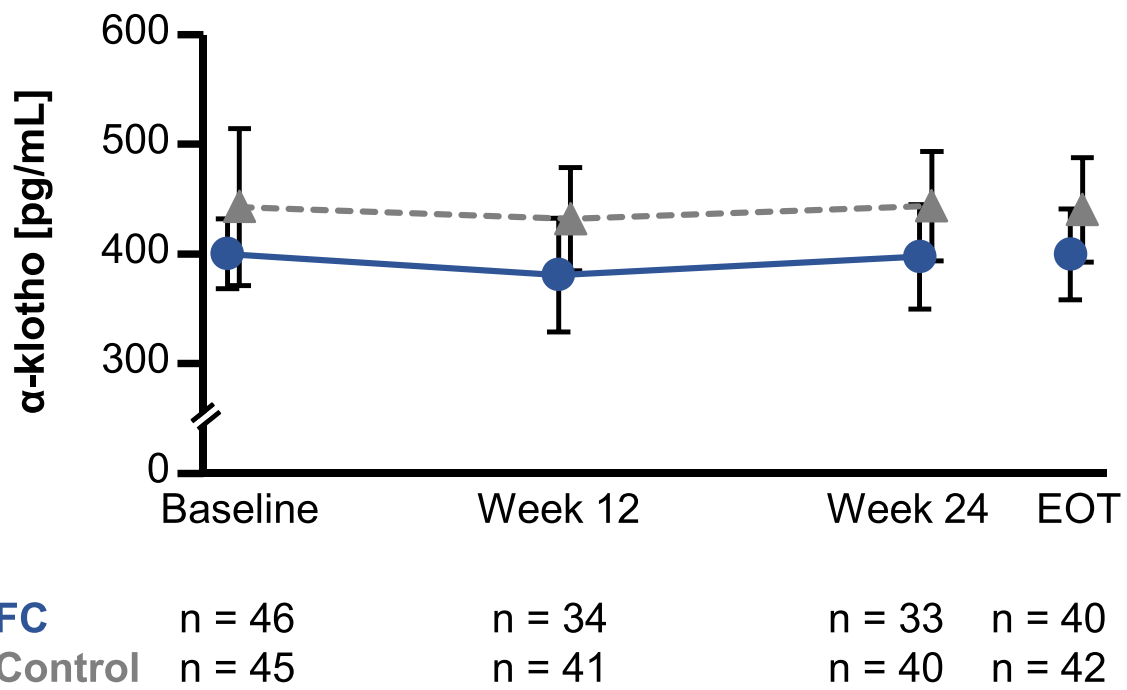

Fig. 3 Time-course changes in levels of biomarkers. Changes in (a) intact fibroblast growth factor-23 (FGF23), (b) C-terminal FGF23, and (c) a-klotho. Data are presented as means and upper and lower limits of the $95 \%$ confidence interval. FC, ferric citrate hydrate; EOT, end of treatment 

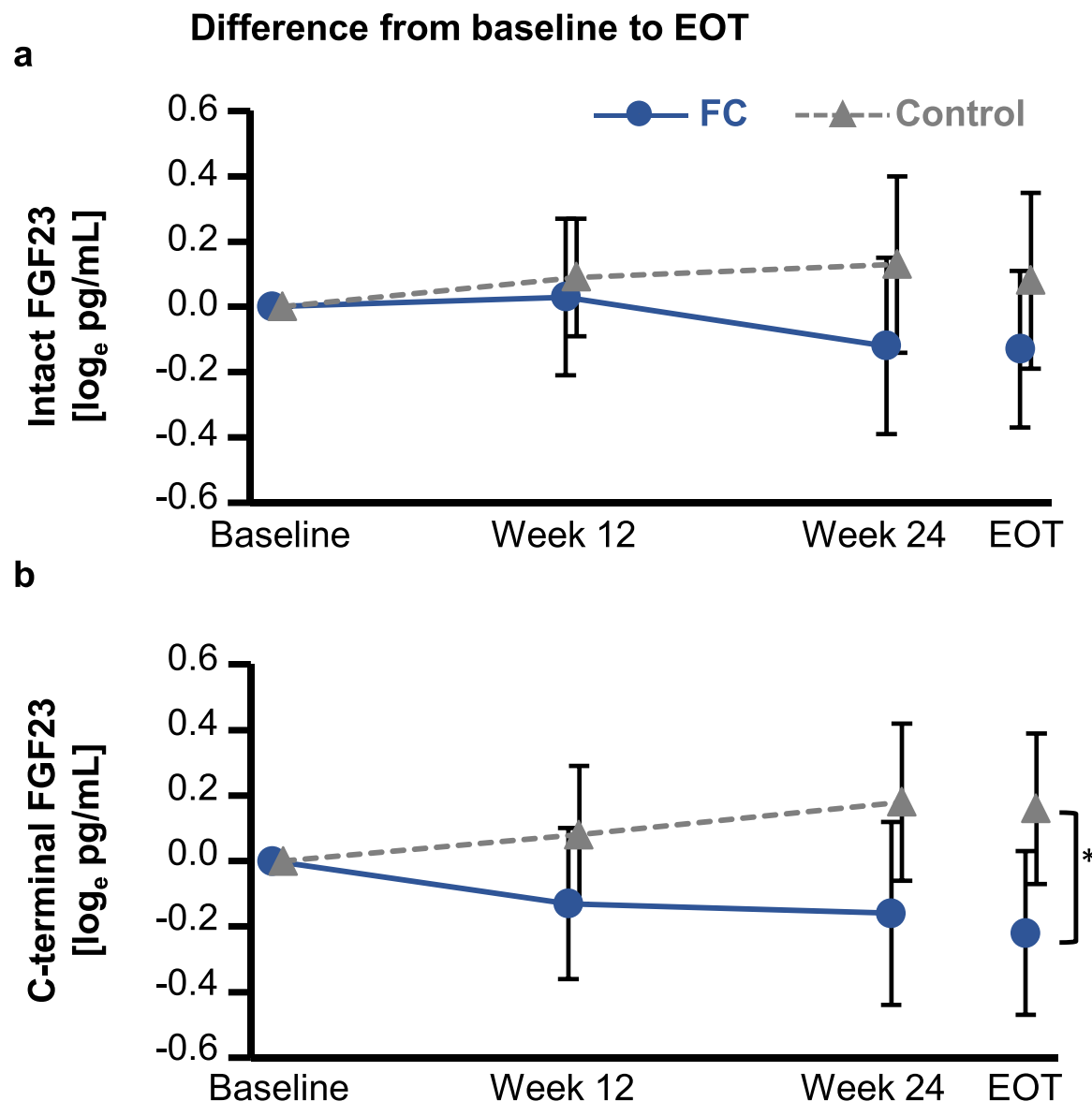

C

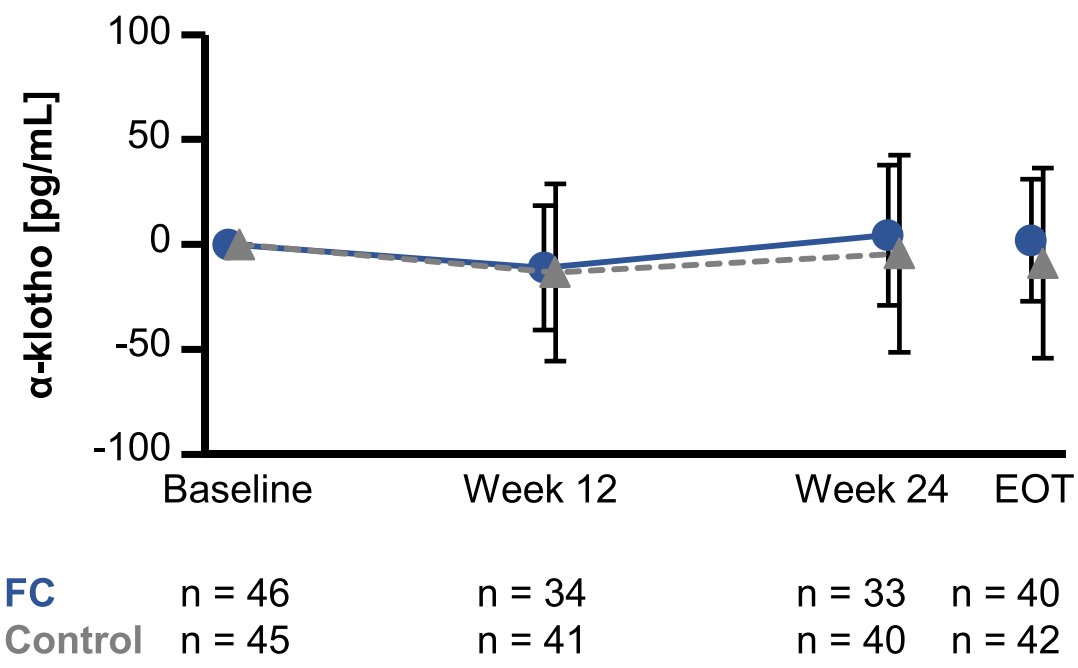

Fig. 4 Time-course changes in difference from baseline to end-of-treatment (EOT) in levels of biomarkers. Changes in (a) intact fibroblast growth factor-23 (FGF23), (b) C-terminal FGF23, and (c) a-klotho. The asterisk in panel (b) designates a statistically significant difference between the control and FC groups $(p=0.04)$. Data are presented as means and upper and lower limits of the $95 \%$ confidence interval. FC, ferric citrate hydrate 


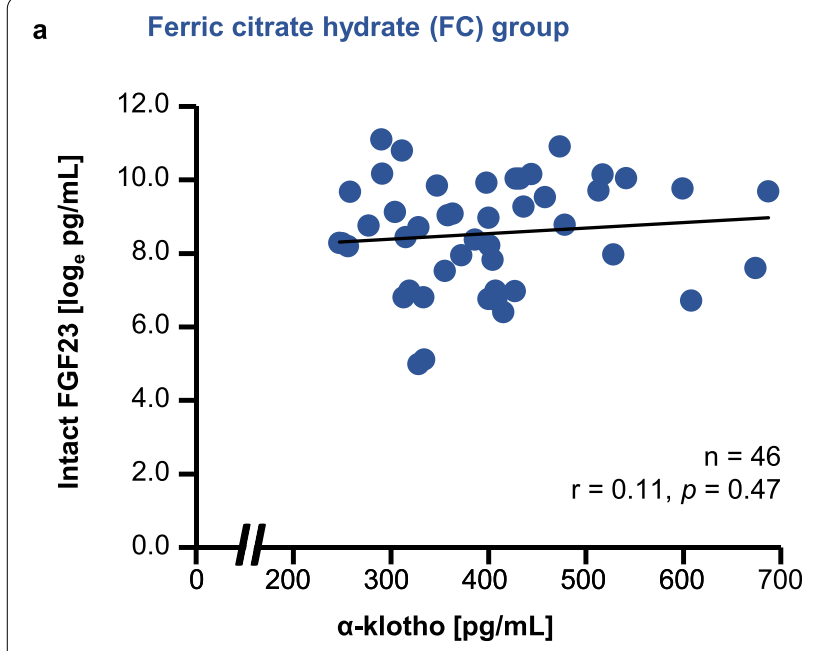

b

Control group

c
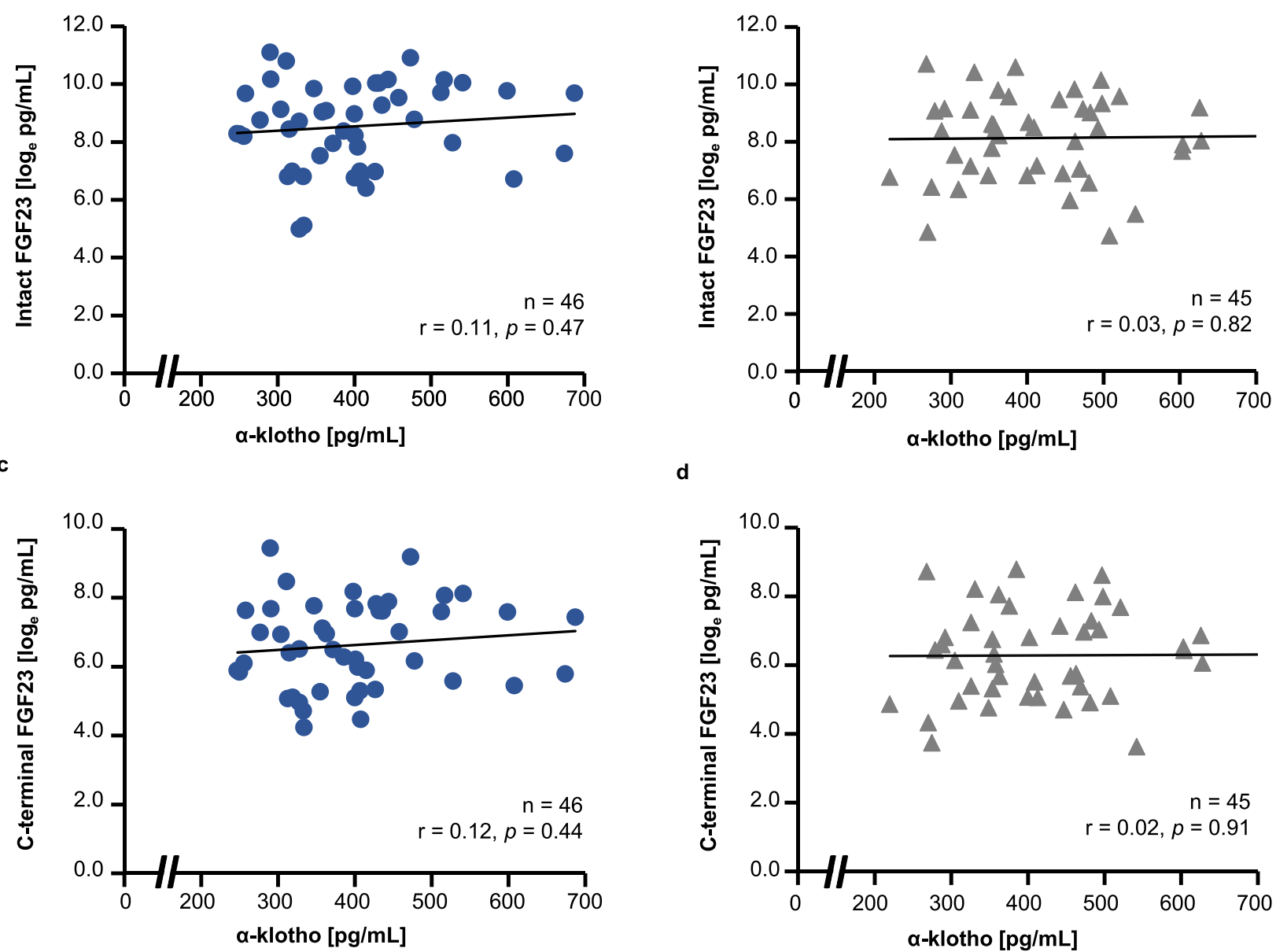

d

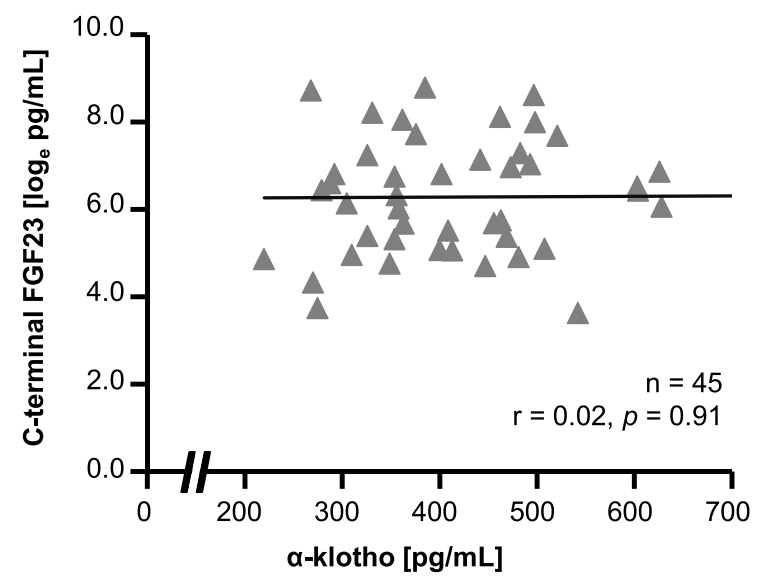

Fig. 5 Association between baseline a-klotho levels and intact or C-terminal fibroblast growth factor 23 (FGF23). (a) a-klotho vs. intact-FGF23 (i-FGF23) in the ferric citrate hydrate (FC) group; b) a-klotho vs. i-FGF23 in the control group; (c) a-klotho vs. C-terminal-FGF23 (c-FGF23) in the FC group; and (d) a-klotho vs. c-FGF23 in the control group. FGF23 values were log-converted. r, Pearson's correlation coefficient

statistically significant but may have been insufficient to stimulate klotho synthesis. A preclinical study using a rat model of ischemic acute renal failure demonstrated that ischemic lesions reduced klotho synthesis immediately, although it recovered after 4 days [32]. Whether klotho synthesis can be restored in chronically damaged kidneys in human patients is unknown and should be investigated in further studies.

Furthermore, it is tempting to speculate that FC treatment did not cause elevated $\alpha$-klotho levels because the $\mathrm{Hb}$ level remained stable. In patients undergoing $\mathrm{HD}$, the levels of sKL was reportedly positively related to $\mathrm{Hb}(p<0.05)$ [33], and a previous 12 -week study of FC compared with sevelamer hydrochloride in patients undergoing $\mathrm{HD}$, the FC group significantly increased $\mathrm{Hb}$ compared with the sevelamer hydrochloride group $(p<0.001)$, whereas there was no difference in the change of serum $\mathrm{P}$ between the groups $(p=0.53)$; however, FGF23 and $\alpha$-klotho levels were not evaluated in the previous study [34].

The current study had several limitations. First, the sample size of participants was small and more patients discontinued treatment due to adverse events in the FC group (eight patients) than in the control group (one patient). This difference may have been influenced by the study design, in which patients who were randomized to the FC group switched treatment from non-iron based phosphate binders to FC at baseline. Second, this study was a post hoc analysis and the sample size was calculated using a change in ESA dose per week as the primary endpoint. Therefore, the sample size may have had insufficient power to detect differences in changes of FGF23 or $\alpha$-klotho, or their association. Third, the evaluation of these biomarkers was performed at three or fewer time 


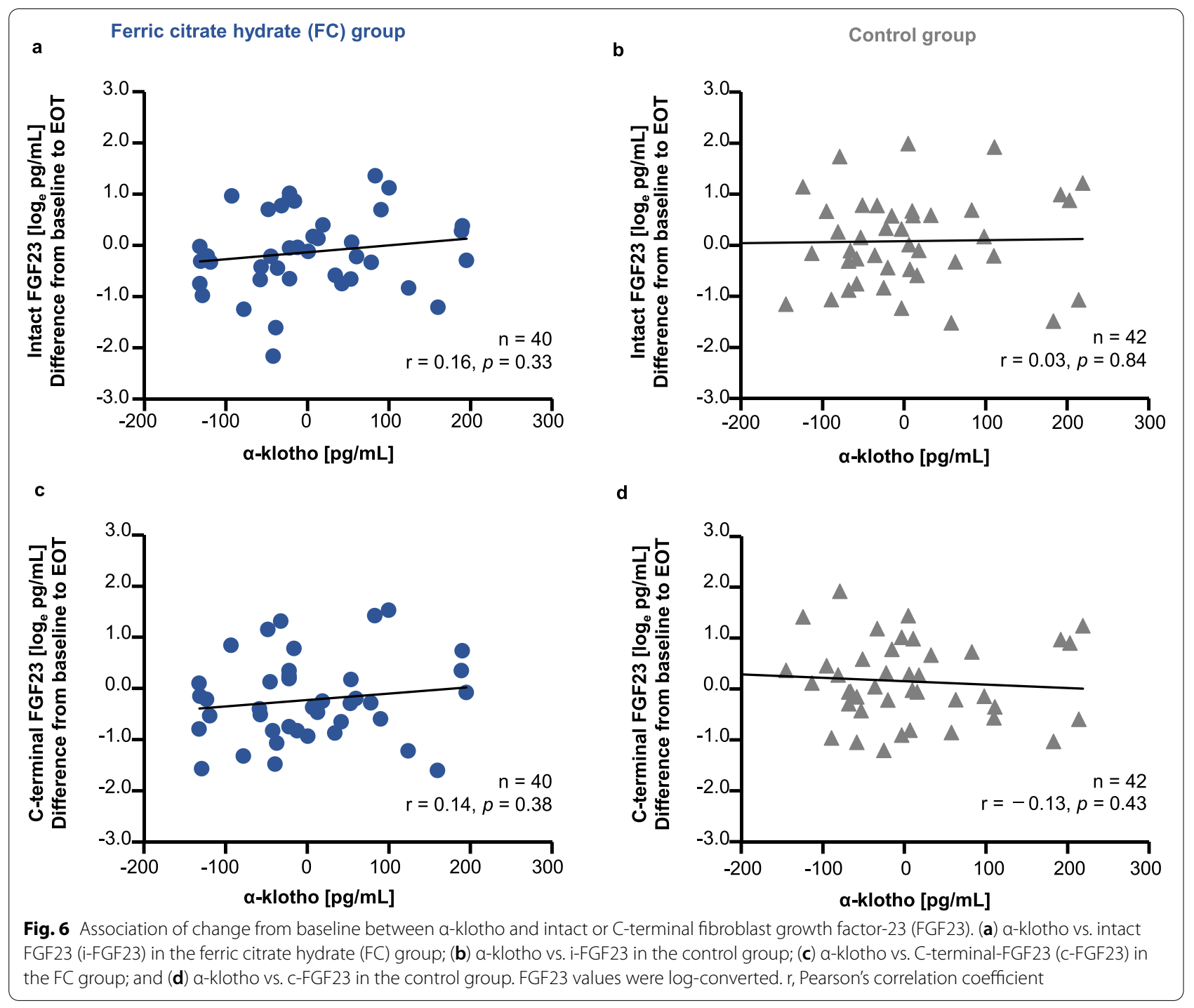

points (baseline, weeks 12 and 24, and at study termination when applicable), which may have been inadequate for the relatively short study period. The study was also limited by its relatively short duration ( 24 weeks), and further evaluations may be needed. Fourth, to avoid the false discovery rate, multiple testing correction might be effective, however we have not conducted it. Finally, although the klotho protein has two forms, mKL and sKL [10], we only evaluated sKL, and the additional evaluation of mKL may have altered the results.

\section{Conclusions}

In conclusion, when serum $\mathrm{P}$ and $\mathrm{Hb}$ were maintained at $10-12 \mathrm{~g} / \mathrm{dL}$ and $3.5-6.0 \mathrm{mg} / \mathrm{dL}$, respectively, we found that treatment with $\mathrm{FC}$, an iron-based phosphate binder, let to significantly elevated serum ferritin from baseline to EOT, as well as significantly reduced ESA dose per week and plasma c-FGF23 level from baseline to EOT, compared with those parameters in patients who received treatment with non-iron-based phosphate binders. The iron absorbed during FC administration presumably contributed to anemia management and reduced FGF23 production. However, our findings showed no correlation relationship between the plasma levels of either form of FGF23 and $\alpha$-klotho in patients undergoing HD.

\section{Abbreviations}

FGF: Fibroblast growth factor; FC: Ferric citrate hydrate; EOT: End-of-treatment; C-FGF23: C-terminal fibroblast growth factor 23; i-FGF23: Intact fibroblast growth factor 23; CKD: Chronic kidney disease; Hb: hemoglobin; $\mathrm{mKL}$ :

Transmembrane a-klotho; sKL: Secreted a-klotho; HD: Hemodialysis; ESA: Erythropoiesis-stimulating agent; P: Phosphate; JSDT: Japanese Society for Dialysis Therapy. 


\section{Acknowledgements}

We thank Mr. Minoru Kudo and Mr. Naoki Muramatsu, who are current employees, and Mr. Yusuke Tanaka and Mr. Toshiaki lida, who were former employees, of the Torii Pharmaceutical Co., Ltd. (Torii), for supporting this work. Monitoring, data management, and all statistical analyses of the ASTRIO study were carried out by Sogo Rinsho Medefi Co., Ltd. (Tokyo, Japan). The findings of this study were partially presented at the American Society of Nephrology, Oct 25-28, 2018, San Diego, CA, USA. ASCA Corporation provided medical writing and editing services.

\section{Authors' contributions}

K. Ito and K. Yokoyama performed the post hoc analysis and interpreted the data. K. Ito drafted the manuscript and K. Yokoyama extensively and critically reviewed the manuscript. All authors reviewed and approved the final version of the manuscript

\section{Funding}

This study was supported by Torii Pharmaceutical Co., Ltd. and Japan Tobacco Inc.

\section{Availability of data and materials}

The datasets generated and/or analyzed during the study are available from the corresponding author on reasonable request.

\section{Declarations}

\section{Ethics approval and consent to participate}

The protocol was reviewed and approved by an independent ethics committee and the Institutional Review Board of The Jikei University School of Medicine. All participants provided written informed consent before starting the study.

\section{Consent for publication}

Not applicable.

\section{Competing interests}

K.I. is an employee of Torii; K.Y. received consulting fees from Torii, Japan Tobacco Inc. and Kyowa Kirin Co., Ltd.; M.N. received consulting fees from Torii; M.F. received consulting fees from Torii, Japan Tobacco Inc. and Bayer Yakuhin Ltd., and research grant and consulting fees from Kyowa Kirin Co., Ltd. and Chugai Pharmaceutical Co., Ltd.; and H.H. received consulting fees from Torii and Japan Tobacco Inc.

\section{Author details}

${ }^{1}$ Medical Affairs Department, Torii Pharmaceutical Co. Ltd., Tokyo, Japan.

${ }^{2}$ Health Care Center, Harumi Toriton Clinic, The Jikei University Hospital, 1-8-8 Harumi, Chuo-ku, Tokyo 104-0053, Japan. ${ }^{3}$ St. Luke's International University, St. Luke's International Hospital, Tokyo, Japan. ${ }^{4}$ Division of Nephrology, Endocrinology and Metabolism, Tokai University School of Medicine, Isehara, Japan.

${ }^{5}$ Fukuoka Renal Clinic, Fukuoka, Japan.

Received: 10 May 2021 Accepted: 25 October 2021

Published online: 10 November 2021

\section{References}

1. Noordzij M, Cranenburg EM, Engelsman LF, Hermans MM, Boeschoten EW, Brandenburg VM, et al. Progression of aortic calcification is associated with disorders of mineral metabolism and mortality in chronic dialysis patients. Nephrol Dial Transplant. 2011;26:1662-19.

2. Ueda N, Takasawa K. Impact of inflammation on ferritin, hepcidin and the management of iron deficiency anemia in chronic kidney disease. Nutrients. 2018;10:1173.

3. Donate-Correa J, Muros-de-Fuentes M, Mora-Fernández C, NavarroGonzález JF. FGF23/Klotho axis: phosphorus, mineral metabolism and beyond. Cytokine Growth Factor Rev. 2012;23:37-46.

4. Rhee Y, Bivi N, Farrow E, Lezcano V, Plotkin LI, White KE, et al. Parathyroid hormone receptor signaling in osteocytes increases the expression of fibroblast growth factor-23 in vitro and in vivo. Bone. 2011;49:636-43.
5. Masuyama R, Stockmans I, Torrekens S, Van Looveren R, Maes C, Carmeliet $P$, et al. Vitamin D receptor in chondrocytes promotes osteoclastogenesis and regulates FGF23 production in osteoblasts. J Clin Invest. 2006;116:3150-9.

6. Edmonston D, Wolf M. FGF23 at the crossroads of phosphate, iron economy and erythropoiesis. Nat Rev Nephrol. 2020;16:7-19.

7. Hu MC, Shiizaki K, Kuro-o M, Moe OW. Fibroblast growth factor 23 and Klotho: physiology and pathophysiology of an endocrine network of mineral metabolism. Annu Rev Physiol. 2013;75:503-33.

8. Mehta R, Cai X, Hodakowski A, Lee J, Leonard M, Ricardo A, et al. Fibroblast growth factor 23 and anemia in the chronic renal insufficiency cohort study. Clin J Am Soc Nephrol. 2017;12:1795-803.

9. Mehta R, Cai X, Lee J, Scialla J, Bansal N, Sondheimer JH, et al. Association of fibroblast growth factor 23 with atrial fibrillation in chronic kidney disease, from the chronic renal insufficiency cohort study. JAMA Cardiol. 2016;1:548-56.

10. Heijboer AC, Blankenstein MA. Hoenderop J, de Borst MH, Vervloet MG; NIGRAM consortium. Laboratory aspects of circulating a-Klotho. Nephrol Dial Transplant. 2013;28:2283-7.

11. Kurosu H, Ogawa Y, Miyoshi M, Yamamoto M, Nandi A, Rosenblatt KP, et al. Regulation of fibroblast growth factor-23 signaling by klotho. J Biol Chem. 2006:281:6120-3.

12. Urakawa I, Yamazaki Y, Shimada T, lijima K, Hasegawa H, Okawa K, et al. Klotho converts canonical FGF receptor into a specific receptor for FGF23. Nature. 2006:444:770-4.

13. Matsumura Y, Aizawa H, Shiraki-lida T, Nagai R, Kuro-o M, Nabeshima Y. Identification of the human klotho gene and its two transcripts encoding membrane and secreted klotho protein. Biochem Biophys Res Commun. 1998;242:626-30.

14. Imura A, Iwano A, Tohyama O, Tsuji Y, Nozaki K, Hashimoto N, et al. Secreted Klotho protein in sera and CSF: implication for post-translational cleavage in release of Klotho protein from cell membrane. FEBS Lett. 2004;565:143-7.

15. Richter B, Faul C. FGF23 actions on target tissues - with and without klotho. Front Endocrinol (Lausanne). 2018:9:189.

16. Hu MC, Moe OW. Klotho as a potential biomarker and therapy for acute kidney injury. Nat Rev Nephrol. 2012;8:423-9.

17. Koh N, Fujimori T, Nishiguchi S, Tamori A, Shiomi S, Nakatani T, et al. Severely reduced production of klotho in human chronic renal failure kidney. Biochem Biophys Res Commun. 2001;280:1015-20.

18. Neyra JA, Hu MC, Moe OW. Klotho in clinical nephrology: diagnostic and therapeutic implications. Clin J Am Soc Nephrol. 2020;16:162-76.

19. Xu Y, Peng H, Ke B. a-Klotho and anemia in patients with chronic kidney disease patients: a new perspective. Exp Ther Med. 2017;14:5691-5.

20. Wang Q, Su W, Shen Z, Wang R. Correlation between soluble a-Klotho and renal function in patients with chronic kidney disease: a review and meta-analysis. Biomed Res Int. 2018;2018:9481475.

21. Yokoyama K, Fukagawa M, Akiba T, Nakayama M, Ito K, Hanaki K, et al. Randomised clinical trial of ferric citrate hydrate on anaemia management in haemodialysis patients with hyperphosphataemia: ASTRIO study. Sci Rep. 2019;9:8877.

22. Fukagawa M, Yokoyama K, Koiwa F, Taniguchi M, Shoji T, Kazama JJ, et al. Japanese Society for Dialysis Therapy: clinical practice guideline for the management of chronic kidney disease-mineral and bone disorder. Ther Apher Dial. 2013;17:247-88.

23. Yamamoto H, Nishi S, Tomo T, Masakane I, Saito K, Nangaku M, et al. 2015 Japanese Society for Dialysis Therapy: guidelines for renal anemia in chronic kidney disease. Ren Replace Ther. 2017;3:36-81.

24. Yamazaki Y, Imura A, Urakawa I, Shimada T, Murakami J, Aono Y, et al. Establishment of sandwich ELISA for soluble alpha-Klotho measurement: age-dependent change of soluble alpha-Klotho levels in healthy subjects. Biochem Biophys Res Commun. 2010;398:513-8.

25. Wan M, Smith C, Shah V, Gullet A, Wells D, Rees L, et al. Fibroblast growth factor 23 and soluble klotho in children with chronic kidney disease. Nephrol Dial Transplant. 2013;28:153-61.

26. Isakova T, Wahl P, Vargas GS, Gutiérrez OM, Scialla J, Xie H, et al. Fibroblast growth factor 23 is elevated before parathyroid hormone and phosphate in chronic kidney disease. Kidney Int. 2011;79:1370-8.

27. Liabeuf S, Ryckelynck JP, El Esper N, Ureña P, Combe C, Dussol B, et al. Randomized clinical trial of sevelamer carbonate on serum klotho and fibroblast growth factor 23 in CKD. Clin J Am Soc Nephrol. 2017;12:1930-40. 
28. Yokoyama K, Hirakata H, Akiba T, Fukagawa M, Nakayama M, Sawada K, et al. Ferric citrate hydrate for the treatment of hyperphosphatemia in nondialysis-dependent CKD. Clin J Am Soc Nephrol. 2014;9:543-52.

29. Maruyama N, Otsuki T, Yoshida Y, Nagura C, Kitai M, Shibahara N, et al. Ferric citrate decreases fibroblast growth factor 23 and improves erythropoietin responsiveness in hemodialysis patients. Am J Nephrol. 2018;47:406-14.

30. Kawabata C, Komaba H, Ishida H, Nakagawa Y, Hamano N, Koizumi M, et al. Changes in fibroblast growth factor 23 and soluble Klotho levels after hemodialysis initiation. Kidney Med. 2019;2:59-67.

31. Kaludjerovic J, Komaba H, Sato T, Erben RG, Baron R, Olauson H, et al. Klotho expression in long bones regulates FGF23 production during renal failure. FASEB J. 2017;31:2050-64.

32. Sugiura H, Yoshida T, Mitobe M, Yoshida S, Shiohira S, Nittaet K, et al. Klotho reduces apoptosis in experimental ischaemic acute kidney injury via HSP-70. Nephrol Dial Transplant. 2010;25:60-8.
33. Yu L, Kang L, Ren XZ, Diao ZL, Liu WH. Circulating a-klotho levels in hemodialysis patients and their relationship to atherosclerosis. Kidney Blood Press Res. 2018:43:1174-82.

34. Yokoyama K, Akiba T, Fukagawa M, Nakayama M, Sawada K, Kumagai Y, et al. A randomized trial of JTT-751 versus sevelamer hydrochloride in patients on hemodialysis. Nephrol Dial Transplant. 2014;29:1053-60.

\section{Publisher's Note}

Springer Nature remains neutral with regard to jurisdictional claims in published maps and institutional affiliations.
Ready to submit your research? Choose BMC and benefit from:

- fast, convenient online submission

- thorough peer review by experienced researchers in your field

- rapid publication on acceptance

- support for research data, including large and complex data types

- gold Open Access which fosters wider collaboration and increased citations

- maximum visibility for your research: over $100 \mathrm{M}$ website views per year

At BMC, research is always in progress.

Learn more biomedcentral.com/submissions 